\title{
EU ETS, Free Allocations and Activity Level Thresholds The Devil Lies in the Detail
}

\author{
Frédéric Branger \\ Jean-Pierre Ponssard \\ Oliver Sartor \\ Misato Sato
}

CESIFO WORKING PAPER NO. 5394

CATEGORY 10: ENERGY AND CLIMATE ECONOMICS

JUNE 2015

An electronic version of the paper may be downloaded

- from the SSRN website:

- from the RePEc website:

- from the CESifo website:

WwW.SSRN.com

www.RePEc.org

www.CESifo-group.org/wp 


\title{
EU ETS, Free Allocations and Activity Level Thresholds The Devil Lies in the Detail
}

\begin{abstract}
This paper investigates incentives for firms to increase output above the activity level thresholds (ALTs) in order to obtain more free allowances in the EU Emissions Trading Scheme. While ALTs were introduced in order to reduce excess free allocation to low-activity installations, for installations operating below the threshold, the financial gain from increasing output to reach the threshold may outweigh the costs, particularly in carbon intensive sectors with a high carbon to production costs ratio. Using installation level data for 246 clinker plants, we estimate the effect of ALTs on output decisions. In 2012, ALTs induced 6.4Mt of excess clinker production (5\% of total EU output), which corresponds to 5.8Mt of excess CO2 emissions (over $5 \%$ of total sector emissions). As intended, ALTs do reduce overallocation (by 6.4 million allowances) relative to a scenario without ALTs, but this gain is small compared to an output based allocation method, which would further reduce overallocation by 40 million allowances $(29 \%$ of total cement sector free allocation). Firms responded disproportionately to ALTs in crisis-hit countries with low demand, especially in Spain and Greece. The excess clinker output lead to increased EU clinker and cement exports, production shifting between plants and also an increase in clinker content of cement thus reducing the carbon efficiency of cement production.
\end{abstract}

JEL-Code: D240, H230, L230, L610.

Keywords: activity level thresholds, EU ETS, carbon trading, free allowance allocations, cement.

Frédéric Branger
CIRED / Paris / France
branger@center-cired.fr

Oliver Sartor

IDDRI / Paris / France

oliver.sartor@iddri.org
Jean-Pierre Ponssard

CNRS \& Ecole Polytechnique / France jean-pierre.ponssard@polytechnique.edu

*corresponding author

18th May 2015

Forthcoming in the Journal of the Association of Environmental and Resource Economists. 


\section{Introduction}

Starting from Phase 3, the EU Emissions Trading System introduced a new rule which links the level of free allocation to the activity level of an installation - known as activity level thresholds (ALTs). Whilst put in place with the intention to reduce excess free allocation to low-activity plants, the new rule creates incentives for installations to 'game' output levels in order to maximise free allocation. This paper measures the distortionary effects resulting from ALTs, by exploiting the natural experiment of the introduction of the new rule in 2012, and discusses whether the disadvantages of ALTs outweigh the advantages.

The justification for using free allocations in emission trading schemes has evolved over time. Historically, in schemes such as the U.S. acid rain program, it was introduced as a compensation mechanism for the owners of existing industrial assets for a change in the rules of the game (Ellerman et al. 2000). A lump sum transfer would be made to existing assets through a predetermined amount of annual free allocations for a given number of years. Such methods are termed "grandfathering", "historic", "lump-sum" or "ex-ante" allocation. New assets would not be allowed free allocations and thus would have to pay for all their permits on the market. As long as the free allocations are predetermined, all assets (old and new) would compete on the same playing field, the price of permits would provide the same opportunity cost for mitigating pollution, and in theory, the output price of the goods sold would incorporate the price signal for consumers.

More recently, free allocations have been explicitly used (or have been proposed to be used) as a way to strategically alleviate the risk of offshoring production and emissions (so-called "carbon leakage") for Energy-Intensive and Trade-Exposed (EITE) sectors such as cement, chemicals and steel. Economists generally agree that, in a world of unequal carbon prices, full auctioning together with some form of border levelling of prices would be the second best approach to tackling leakage (Hepburn et al. 2006, Monjon and Quirion 2011). However, the required degree of international cooperation to achieve such a system has not yet been forthcoming. Thus, a number of papers suggest that, from an economic efficiency standpoint, free "output-based" allocation (OBA) would be a preferred third-best option (Fischer and Fox 2007, Quirion 2009, Fischer and Fox 2012, Meunier, Ponssard and Quirion 2014). OBA reduces the effect of the carbon price on the output price, which reduces trade distortions, but also means that the final price does not fully reflect the carbon price, which reduces efficiency. The overall effect may be welfare enhancing relative to either full auctioning or ex-ante free allocations.

An OBA scheme has been implemented within the Californian ETS which began in 2012 (California Air Resources Board 2013). In contrast the EU ETS Phase 3 is unique in using a complex system. It combines an ex-ante calculation ${ }^{6}$ of an allocation and subsequent lumpsum transfer based on historic output (and multiplied by an emissions intensity benchmark) with a possible ex-post calculation and adjustment of this lump-sum according to rules related to actual capacity and activity levels as defined in Decision (2011/278/EU) (European Commission 2011). Situations in which ex-post adjustments occur include the arrival of new entrants into the market, plant capacity extension/reduction, plant closure and partial

\footnotetext{
${ }^{6}$ Note that ex-ante and ex-post refer to whether the calculation of the freely allocated amount of allowances occurs prior to or following the production and emissions for which allowances are to be allocated.
} 
cessation or recommencement of activity at an existing plant. These latter rules are governed by the activity level thresholds (ALTs). ${ }^{7}$

Qualitatively, ETS schemes with ALTs approximate OBA: the amount of free allocations will vary with the activity level, and the over allocation profits ${ }^{8}$ associated with ex-ante schemes will be reduced. ${ }^{9}$ The advantage of ALTs rules is that they allow for a fixed cap (in fact a cap which will not exceed a predetermined amount for existing installations and the reserve for new entrants). One disadvantage is that they introduce an element of complexity in the scheme. Under these non-linear rules, the lump sum transfer of allowances to EITE sectors is reduced by $50 \%, 75 \%$ or $100 \%$ if the annual level of production of the plant falls below $50 \%$, $25 \%$ or $10 \%$ respectively, of the historical activity level (HAL) of production that is used to determine the ex-ante allocation (European Commission 2011).

A second disadvantage is that the ALTs introduce distortions, which is the focus of this paper. A recent study on the EU ETS impacts on the cement sector 2005-2013 (Neuhoff et al. $2014)^{10}$ found preliminary evidence through data analysis and comprehensive interviews with industry executives, that new ALTs introduced in 2013 provided cement installations the incentive to adjust output levels. The rationale is as follows. Since the free allocation in year $t+1$ is directly linked to output in year $t$, if output levels lie below the threshold levels, there may be an incentive to increase output in year $t$ to achieve the relevant threshold (.10, $.25, .50)$ and receive higher free allocations in year $t+1$. In this paper, such strategic adjustments of output motivated by ALTs are termed "gaming" behaviour, in line with the management literature (e.g. Jensen 2003). Neuhoff et al. (2014) report, in interviews, that company executives consistently confirm these practices where the regional cement market demand is insufficient to reach the minimum activity level. They identify three channels to marginally increase production in a plant which is producing below the threshold:

- Production shifting among local plants, i.e. reducing the production at a plant which is well above the threshold to increase the production at the plant which is below; this generates some transport costs ${ }^{11}$ so that it can be too costly to be undertaken at a large scale;

- Exports of clinker to other markets so as not to perturb the local market while increasing production; this generates some cost in terms of export price rebate, since these exports would not naturally occur;

- Increase the clinker to cement ratio, i.e. incorporate within limits more clinker in cement instead of using less costly cementitious additives such as slag or flying ashes; this directly generates some cost.

In this paper we revisit the existence and the magnitude of the distortions, and ask whether or not the installation outputs and trade flows in 2012 affected by the free allocation policy

\footnotetext{
${ }^{7}$ New entrant provision and closing rules were already in place in Phases 1 and 2 of the EU-ETS. A closure rule is also used in the Californian ETS.

${ }^{8}$ Over allocation profits come from the allowances surplus automatically generated when the number of free allowances received is higher than emissions necessary to manufacture the amount of cement produced (Branger and Quirion 2015). Over allocation profits can be distinguished from windfall profits, which refer to the profits from free allocation where emitters additionally profit from passing on the marginal $\mathrm{CO}$ opportunity cost to product prices, despite receiving the allowances for free. Over allocation profits can occur even in the absence of cost pass through, if output fall short of historic levels.

${ }^{9}$ Windfall and over allocation gains have been a persistent shortcoming of the use of ex-ante free-allocation mechanism in the EU ETS (e.g. Laing et al. 2014, Sartor et al. 2014, and Sandbag 2011).

${ }^{10}$ Three co-authors of this paper participated in this study and in conducting interviews that were carried out.

${ }^{11}$ McKinsey (2008) estimate that transport costs for a tonne of clinker from Alexandria to Rotterdam are roughly $€ 20 /$ tonne, and that inland shipping costs are approximately $€ 3.5 /$ tonne per $100 \mathrm{~km}$ and inland road transport was about $8.6 € /$ ton per $100 \mathrm{~km}$.
} 
change for year 2013. Our analysis is conducted in a unique context of low demand induced by a severe economic downturn. The construction of a counterfactual requires some assumptions, the most significant of which considers that consumption and price levels for cement are independent of the allocation scheme. This assumption is consistent with the observations made in Neuhoff et al. (2014). We discuss in detail how our results would be affected if we had adopted the more standard assumption in which grandfathering and output based allocation would lead to different cement and price levels.

Empirical studies on the impact of ALTs or similar rules remain limited. Most of these studies have examined the distortive effects of combined ex-ante allocations with ex-post new entrant and plant closure provisions. Pahle, Fan and Schill (2011), Ellerman (2008) and Neuhoff, Keats and Sato (2006) compared the new entrant provision relative to auctioning. These papers argued that new entrant provisions distort via their impact on investment decisions in the electricity sector (essentially by acting as a subsidy). Meunier et al. (2014) compared this same provision with an output-based scheme whenever firms face an uncertain demand in the EU cement sector. They showed the entrant provision could induce excessive new investments while offering limited protection against leakage. Fowlie,Reguant and Ryan (Forthcoming), this time for the US cement sector, compare ex-ante schemes with closure rules with an output-based scheme and show that the lifetime of old inefficient plants would be unduly extended with the former while temporarily reducing leakage. Only this last paper has discussed the impacts of the possible distortions associated with the (limited) addition of "non-linear" ex-post adjustments to ex-ante allocation via the use of ALTs, such as introduced in the EU ETS Phase 3 (2013-2020).

The findings in this paper could be potentially relevant to other EITEs with similar characteristics. Altogether, we argue that the benefits of implementing ALTs in terms of reduced over allocation profits will not necessarily outweigh the significant costs in the form of distortions. Hence it may be preferable to abandon ALTs for OBA for some sectors. We discuss some broader questions if such a change were adopted.

The paper is organized as follows. Section 2 discusses the EU ETS Phase 3 allocation rules, the predicted gaming behaviour from thresholds and the alternative allocation rules. Section 3 describes our conceptual framework for evaluating the effects of ALTs, the methodology, data sources, as well as the key assumptions involved in our analysis. Section 4 presents the results. Section 5 concludes and discusses policy recommendations.

\section{ETS free allocation rules and gaming of ALTS}

\subsection{The EU-ETS Phase 3 free allocation rules}

In Phase 3 of the EU ETS, installations in sectors "deemed to be exposed to carbon leakage" are eligible to receive free allocation of emission allowances. The determination of the free allowances for each installation combines an ex-ante calculation, based on the historic output for existing installations (known as the "historical activity level" or "HAL"12) or the initial capacity for new installations, with an ex-post calculation based on the ongoing activity level of this installation as defined in Decision (2011/278/EU) (European Commission 2011). The ex-post calculation provides step wise adjustments intended to reflect changes in market volumes. These adjustments follow complex procedures.

\footnotetext{
${ }^{12}$ The benchmarked product-related historical activity level (HAL) is defined as maximum of the median annual historical production of the product in the installation (or sub-installation) concerned during either 2005-2008 or 2009-2010. (cf. Decision (2011/278/EU)).
} 
For existing installations, the precise relationship that determines the next-period allocation from ex-ante and ex-post values is summarised by Equations 1 and 2 below. The amount of free allocations to an installation, $i$, at period $t+1$, for an eligible product, $p$ is denoted $A_{i, p, t+1}$.

$$
A_{i, p, t+1}=\operatorname{CSCF}_{t+1} \times B_{p} \times H A L_{i, p} \times A L C F_{t+1}\left(\frac{q_{t}}{H A L_{i, p}}\right)
$$

In equation (1) $C S C F_{t+1}$ is the uniform cross-sectoral correction factor ${ }^{13}, B_{p}$ is the benchmark for product $p,{ }^{14} H A L_{i, p}$ represents the historical activity level; and ALCFis the activity level correction factor, which depends on the ratio $q_{i, p, r} / H A L_{i, p}, q_{i, p, t}$ being the output of the eligible product in year $t$. The ALCF defines a step wise function for the thresholds. It is defined as:

$$
A L C F_{t+1}\left(\frac{q_{t}}{H A L}\right)=\left\{\begin{array}{rc}
1, & q_{t} \geq 0.5 \mathrm{HAL} \\
0.5, & 0.25 \mathrm{HAL} \leq q_{t}<0.5 \mathrm{HAL} \\
0.25, & 0.10 \mathrm{HAL} \leq q_{t}<0.25 \mathrm{HAL} \\
0, & 0 \mathrm{HAL} \leq q_{t}<0.10 \mathrm{HAL}
\end{array}\right.
$$

For new installations, the historic activity level is replaced by the capacity, to be precisely determined according to the rules. ${ }^{15}$

\subsection{Gaming and thresholds}

Gaming behaviour refers to artificially increasing production to attain thresholds, in order to obtain more allowances. Consider a plant for which the "business as usual" activity level for year 2012 would be at say $40 \%$ of its historic activity level. Increasing production up to $50 \%$ of its historic activity level allows doubling the free allocation received. A rough calculation with a clinker plant illustrates the potential benefit of gaming. Suppose HAL refers to 1 Mt/year (millions of metric tons per year), the business as usual is $0.4 \mathrm{Mt}$ in 2012 so that the plant needs to increase production by $0.1 \mathrm{Mt}$ to achieve the $50 \%$ threshold. At $8 € / \mathrm{t} \mathrm{CO}_{2}$ in 2013 (average future price of December 2013 during year 2012), if the firm gets 100\% of free allowances relative to HAL it is worth $5.8 \mathrm{M} €(0.9427 \times 1 \mathrm{Mt} \times 0.766 \mathrm{tCO} 2 / \mathrm{t} \times 8 € / \mathrm{tCO} 2$, numbers being respectively CSCF, HAL, clinker benchmark and carbon price); losing 50\% allowances implies a loss of $2.9 \mathrm{M} €$. Suppose the emission intensity is $0.8 \mathrm{t} \mathrm{CO}_{2} / \mathrm{t}$ of clinker (slightly above the benchmark). The increase in emissions is then equal to $0.080 \mathrm{t} \mathrm{CO}_{2}$ which at $8 € / \mathrm{t} \mathrm{CO}_{2}$ amounts to $0.64 \mathrm{M} €$.

Figure 1: The value of gaming. The installation engages in gaming when $\Delta X<\Delta X_{0}$. I refers to the carbon intensity of the plant. Benefits are the increased free allocations minus increased emissions.

\footnotetext{
${ }^{13}$ This is determined by comparing the sum of preliminary total annual amounts of emission allowances allocated free to installations (not electricity) for each year over the period 2013-2020. In 2013 the CSCF is equal to 0.9427, then declines at $1.74 \%$ per year.

${ }_{14}$ Product benchmarks in general reflect the average performance of the $10 \%$ most efficient installations in the sector or subsector in the years 2007-2008. The benchmarks are calculated for products rather than inputs Decision (2011/278/EU).

${ }^{15}$ Guidance document n'7 in European Commission, 2011.
} 


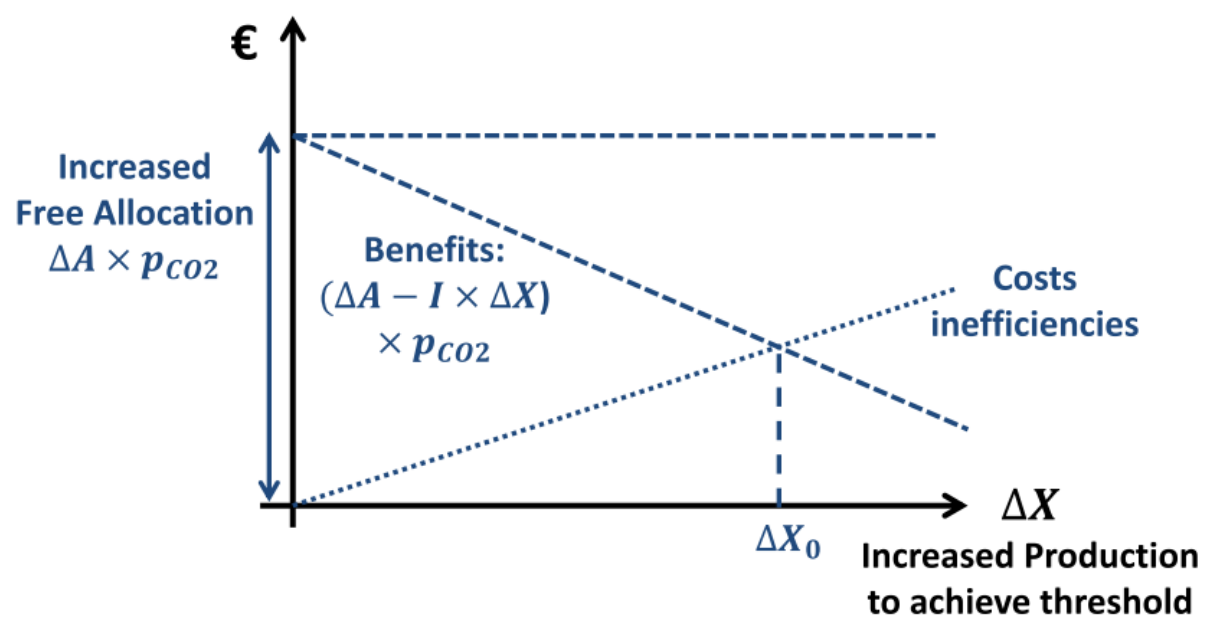

In the presence of activity level thresholds, the net benefit of gaming in terms of allocations is the difference between the increased free allocations and the certificates needed to cover the increased production (in our case $2.26 \mathrm{M} €=2.9 \mathrm{M} €-0.64 \mathrm{M} €$ ). The net benefit depends on the price of $\mathrm{CO}_{2}$, the benefit rising with the price. However, this artificial increase of production involves cost inefficiencies, which can be assumed to be increasing function of the extra production, independent of the $\mathrm{CO}_{2}$ price but dependent on the plant. These cost inefficiencies can up to a point cancel out the gains from increased free allocation. This is shown in Figure 1, where gaming is undertaken only if the increased production to attain the threshold is less than $\Delta X_{0}$. In our case, if the extra production of 0.1 ton of clinker does not involve cost inefficiencies of more than $2.53 \mathrm{M} €$, gaming is profitable.

Evidence of strong responses to thresholds - where small changes in behaviours lead to large changes in outcomes - has been found in the recent literature. Sallee and Slemrod (2012) find evidence that the automakers respond to notches in the Gas Guzzler tax and to mandatory fuel economy labels by manipulating fuel economy ratings in order to qualify for more favourable treatment. The management control literature also finds that managers tend to react strongly to the existence of a threshold. This is the case, for example, when bonuses depend on the achievement of a given level of sales for a sales manager, a given productivity indicator for a plant manager, a given return on investment for a business manager, a given level of the total shareholder return for a CEO, etc (Locke 2001). In a wellknown article, Jensen (2003) points out that such "gaming" behaviour is perfectly rational under threshold rules. He argues that these rules imply an agency cost which is largely underestimated and suggests that linear bonus schemes should be preferable.

\subsection{Alternative free allocation rules}

The EU ETS Phase 3 rules can be compared with an ex ante allocation without ALTs or an output-based allocation scheme. Under OBA, the next period allocation is determined according to an equation similar to equation (1) (with $H A L_{i, p} \times A L C F\left(q_{i, p, t} / H A L_{i, p}\right)$ replaced by $\left.q_{i, p, t}\right)$. The scheme therefore has no thresholds, and the historic activity level $H A L$ is replaced by the previous year activity level $q_{t}$ so as allocations are altered on a continuous yearly production basis. In this paper, we will evaluate the impact of the ALTs by contrasting four scenarios, with their respective acronym:

- Ex-ante free allocation with ALTs (Phase 3 allocation rules) and gaming (EXALTG)

- Ex-ante free allocation with ALTs (Phase 3 allocation rules) without gaming (EXALTNG)

- Ex-ante free allocation without ALTs (EX)

- Ex-post output based allocation (OBA) 
Scenario EXALTG corresponds to what was observed in Phase 3. Scenario EXALTNG applies the same rules but it is a hypothetical scenario where no gaming behaviour is observed (every variable is identical as in EX, except the allocation, which follows a different rule). EXALTNG, EX and OBA represent counterfactuals.

\section{Methodology and data}

Since 2013 is the first year the threshold rule is in place, the 2012 activity level directly determines the allocation of allowances for 2013. The preliminary analysis in Neuhoff et al. (2014) provided evidence of distortions arising from the ALTs rule. The present study quantifies these distortions.

\subsection{The cement sector}

Our analysis focuses on the cement sector ${ }^{16}$ for three reasons. First, it ranks amongst the highest in terms of carbon intensity per value added thus the effects of free allocation rules are magnified. The cement production process can be divided into two basic stages: production of clinker and the subsequent grinding and blending of clinker with other mineral components to produce cement. The first stage (clinker production) accounts for the bulk of carbon emissions in cement production. Allocation under the EU ETS is based on a benchmark on clinker. ${ }^{17}$ The relevant output involved in the threshold rule is then the quantity of clinker produced. As an intermediate product, clinker is more traded among cement producers ${ }^{18}$ than the final product, cement. However, cement is traded as well, hence the analysis has to be done simultaneously for both products.

In terms of geographical segmentation the high cost of land transportation of cement (or clinker) suggests that regional cement consumption be sourced from local plants. Some imports or exports mostly take place through long haul sea transportation (rail or river transportations of cement are not well developed within Europe as opposed for instance to the US). A relevant market is usually defined in reference to competition analysis. It allows for a precise definition of consumption, production facilities, and import and export flows. In the EU this data can be collected at the member state level and a number of antitrust analyses are typically made at this level. In this paper we shall consider that the member state provides the good level of segmentation for our analysis ${ }^{19}$.

Second, as the sector experienced a demand collapse in the order of $50 \%$ or more between 2007 and 2012 in several member states, the ALTs rules were likely to have been a relevant factor for operational decisions during the period studied. Indeed, we suspect that the most important differences between scenarios EX and EXALTG will occur in countries in which cement and clinker consumption in 2012 fell well short of historical consumption level and hence ALTs rules are relevant. For convenience our results obtained for each member state

\footnotetext{
${ }^{16}$ For an overview of the European cement sector see for instance Hourcade et al. (2007) and Boyer and Ponssard (2013).

${ }^{17}$ It could have been based on a cement or a hybrid benchmark instead. The hybrid benchmark avoids the "clinkercement paradox" (Quirion 2009).”. If the benchmarked product is cement, plants have an incentive to outsource clinker production. If it is clinker, the incentive to reduce the clinker-to-cement ratio is lost. In California, the benchmarked product is "adjusted clinker and mineral additives produced", which is equal to $Q_{K}\left(1+\frac{r}{R}\right)$, where $Q_{K}$ is the clinker produced, $R$ is the clinker ratio and $r$ is the "mineral additives ratio" (limestone and gypsum consumed divided by cement produced). This system gives an incentive to use more mineral additives while preventing clinker outsourcing.

${ }^{18}$ International traders do also play a role in this market. Yet in 2011 around 50\% of world cement trading was undertaken by the top five global cement companies (see for instance financial analyst's report Jefferies, 2012, page 153)

${ }^{19}$ Some small countries are regrouped into larger entities which are coherent in terms of regional market (see Section C.1)
} 
will be aggregated. The 26 EU ETS member states ${ }^{20}$ with ETS-participating clinker production plants will be divided into two groups (see Table 1). The first group includes countries where the average domestic cement consumption in 2011-2012 was less than 70\% of 2007 levels. ${ }^{21}$ We name this group "low demand" (LD) countries. Of the LD countries, we present some of the results for Greece and Spain, as these two member states were particularly affected by the downfall. The LD countries represented 51\% of EU ETS cement emissions in 2008 and $40 \%$ in 2012. The remaining countries are classified as "moderate demand" (MD).

Table 1: Moderate- (MD) and low demand (LD) countries in terms of cement consumption in 2012 relative to 2007 levels $^{22}$

\begin{tabular}{|l|l|}
\hline Low Demand (LD) Countries & Moderate Demand (MD) Countries \\
\hline $\begin{array}{l}\text { Ireland, Spain, Greece, Bulgaria, Hungary, } \\
\text { Denmark, Portugal, Italy, Slovenia and Baltic } \\
\text { countries }\end{array}$ & $\begin{array}{l}\text { France, Germany, Netherlands, Norway, } \\
\text { Poland, Romania, Slovakia, Sweden and } \\
\text { United Kingdom }\end{array}$ \\
\hline
\end{tabular}

Third, the cement sector is characterised by relatively homogeneous products and production processes, unlike chemicals and steel for example with many product categories and differentiated impacts. This aspect does not make distortions due to ALTs more likely to occur; but facilitates their quantifications. Indeed, allocation is determined with activity levels $(q / H A L$, in the cement sector, q being the quantity of clinker), but data on output is not publically available at the installation level. However, data on emissions is thanks to the European Union Transactions Log (EUTL). Because of the very strong and direct relationship between production of clinker, a highly homogeneous product, and emissions, it is possible to infer production (activity) from emissions ${ }^{23}$.

\subsection{Conceptual framework and main assumptions}

The quantification of distortions due to the thresholds necessitates the elaboration of counterfactual states of the world for 2012 (what would have happened had the threshold rule not been implemented i.e. under scenarios EX, OBA or had it been implemented and had the firms not reacted strategically) for each relevant market. A straightforward caveat is that our results are then very dependent on the counterfactuals, which is developed by combining historical data at the country and plant level characteristics using a panel data model. We conduct Monte Carlo analysis to assess confidence intervals and conduct a number of robustness tests to limit this caveat.

We consider a "state of the world" as consisting of: ${ }^{24}$

\footnotetext{
${ }^{20}$ Note that Iceland, Liechtenstein, Malta have no listed clinker plants in the EUTL database, while data for Cypriote plants was not able to be exploited due to missing data.

${ }^{21}$ The average of 2011 and 2012 was taken since both years are relevant to the analysis that follows here. 2007 is taken as the reference year since this was the year in which demand peaked in most EU Member States prior to the economic crisis of 2008.

${ }^{22}$ There are no clinker plants in Malta, Lichtenstein and Iceland. Emissions data on two clinker plants of Cyprus is available from 2012 only, hence cannot be used in this analysis.

${ }^{23}$ We use the observed ratio of publically-reported verified emissions (E) relative to the Historical Emissions Level (HEL), to proxy the share of unobserved activity level relative to Historical Activity Level (HAL) i.e. E/HEL $\approx$ q/HAL. This approximation is possible because the emissions intensities of clinker production have changed only very marginally in the EU in recent years between 2005 and 2012 (GNR Database). At first sight, the approximation E/HEL $\approx \mathrm{q} / \mathrm{HAL}$ may turn problematic for precisely distinguishing between installations that are above or below thresholds ( $25 \%$ and $50 \%$ of q/HAL). However, as detailed in Appendix A1, we ensure that installations are correctly identified using 2013 allocations data. This reveals whether or not the installation had seen its allocation reduced because of 2012 activity levels. Further, 2013 allocation data also allowed us to obtain clinker carbon intensity at the plant level, and then to assess production through emissions (see Appendix A.2).

${ }^{24}$ The amount of free allocation received is then excluded from the "state of the world"
} 
- Consumption and price of cement

- Production of clinker and cement, distribution of this production among plants, clinker to cement ratio

- Trade flows of cement and clinker

We know the (actual) state of the world for EX in 2011 and for EXALTG in 2012 thanks to trade and emissions data, the close relationship between emissions and clinker production and to conservation principles. We need to construct counterfactuals for 2012 for OBA, EX and EXATNG. There are two issues: the change in economic conditions from 2011 to 2012 (cement consumption fell by 13\% at the EU level between 2011 and 2012) and the possible impacts of the allocation rules (we expect that ALTs led to an increase in the production of clinker to get a higher level of free allocation).

We now detail our main methodological assumptions. We start with the second issue: the role of the allocation rule.

Hypothesis $\boldsymbol{H}_{\mathbf{1}}$ : the state of the world is identical for OBA, and EX/EXALTNG ${ }^{25}$

We assume that firms take for granted that the ex-ante free allocations have been obtained through a leakage argumentation so that they will not pass through the marginal cost of carbon to consumers. This implies that the only difference in the corresponding counterfactual scenarios refers to the amount of free allocations.

This assumption appears at odds with the economic literature (Fischer and Fox 2007, Demailly and Quirion, 2006) which would clearly distinguish between ex-ante free allocations and ex-post OBA. Ex-ante free allocations do not provide any protection against leakage because the marginal cost of production is not affected (as long as a plant operates ex-ante free allocation only imply a lump sum transfer). In contrast, with ex-post OBA allocations marginal cost is unchanged because free allocation is directly proportional to output, hence there are no competitive impacts with respect to imports. This is the usual argument in favour of OBA. Cement consumption and price would then differ depending on which of these two allocation methods are used.

$H_{1}$ is supported by a series of in-depth interviews with cement sector actors in the EU ETS (Neuhoff et al. 2014, p.26). These interviews point out three reasons why in practice, no price change (cost pass through) was observed in the cement sector so far. First, the ex-ante free allocations were given out, precisely to mitigate carbon leakage. Thus firms perceived a risk of losing future free allocations if they passed through the cost of carbon and there was no leakage. Second, companies reported long term strategic considerations - such as maintaining market share and good client relationships - could partially balance the incentive to pass the carbon price. Third, they perceived the risk of drawing attention of competition authorities due to abnormal profit levels, if the pass-through of the carbon cost lead to large windfall profits. ${ }^{26}$ It is important to note that these empirical observations have been made in a context of low carbon price. We certainly do not claim that $H_{1}$ would prevail at all times.

Hypothesis $\boldsymbol{H}_{2}$ : the cement consumption and price for EXALTG is identical to the one of EX/EXALTNG

\footnotetext{
${ }^{25}$ EX and EXALTNG have by definition the same state of the world and differ only by the allocation method ${ }^{26}$ The UK Competition Commission has argued that UK cement firms enjoyed abnormal profits even without passing through the cost of carbon https://www.gov.uk/cma-cases/aggregates-cement-and-ready-mix-concretemarket-investigation
} 
Since the clinker production is likely to increase through gaming, the question is what happens to the excess production of the plants that game the scheme. This assumption says that this excess production affects the clinker plant distribution, the trade flows and the clinker to cement ratio but not the consumption (quantity and price). From $\mathrm{H}_{2}$ we shall derive the trade flows for the other scenarios through an econometric analysis of the historical trends. The difference between this estimation with the observed trade flows for EXALTNG can be attributed to the introduction of ALT and the gaming.

Neuhoff et al. (2014) indeed identify the three above channels: reshuffling of production among plants (this may be quite easily done since many cement companies are multi-plants), exports to non EU countries and increase in the clinker to cement ratio. The data support the extensive use of these three channels. This does not exclude that a small fraction of the excess production goes into the regional market. Our assumption is that this fraction can be neglected because of the oligopolistic nature of competition. Increasing the regional supply would most certainly depress the price substantially and increasing a plant market share would most certainly induce strong reactions from competitors.

We now come back to the change in the economic conditions. We shall assume that the distribution of clinker production among plants remains proportional to the change in consumption with some corrections for coastal plants and plant capacity. Having estimated counterfactual production levels by installation ${ }^{27}$, we can estimate the number of free allowances (EUA for EU Allowance, which is the official title pollution permits traded in the EU Emissions Trading Scheme) received at the plant level under the various scenarios. ${ }^{28}$

The two hypotheses $H_{1}$ and $H_{2}$ allow us to construct a counterfactual plant activity common to the counterfactual scenarios (EX, EXALTNG and OBA) in the absence of data or models to directly assess the effects of allocation methodologies on consumption and prices. We argue the empirical evidence reported in Neuhoff et al. (2014) is persuasive and supports these assumptions. However, given the discrepancy with the literature, it is important to see how our results would stand if $H_{1}$ or $H_{2}$ were relaxed. This is done in Section 4.7.

To convert the free allocation and emission effects into monetary value, we shall assume a $\mathrm{CO}_{2}$ price at $7.95 € / \mathrm{t}$, which corresponds to the average future price (December 2013) during year $2012^{29}$.

Hypothesis $\boldsymbol{H}_{3}$ : The increased production due to gaming is sold at marginal cost (excluding emission cost), and so has no impact on profits

In practice plants may actually sell their excess production at a higher or lower price, the important point being that the associated revenue be higher than the associated inefficiency costs (see Section 2.2). The precise financial impact is bound to depend on circumstances specific to each plant which are unobservable. $H_{3}$ allows for an estimate of the financial impact.

\footnotetext{
${ }^{27}$ As we perform a Monte Carlo analysis, there is not "a" counterfactual but 10,000. For simplicity, we will explain the reasoning as if there was just one (these different steps are simply repeated for each sample of counterfactual).

${ }^{28}$ As an example, let us consider a plant, which is functioning at 50\% E/HEL and receiving 1 million EUAs.28 Suppose that our econometric model finds that the counterfactual activity level of this plant is $40 \%$. This plant would have received 0.4 million EUAs under OBA, 1 million EUAs under EX and EXALTG, 0.5 million EUAs under EXALTNG. In this short example, we see that gaming from $40 \%$ to $50 \%$ allows obtaining 0.5 MEUAs more allowances, but involves $0.11 \mathrm{Mt}$ CO2 of additional emissions28, so that the net gain in terms of allowances is 0.39 MEUAs.

${ }^{29}$ Source: ICE database (http://data.theice.com/MyAccount/Login.aspx)
} 
In summary, for each scenario, we compute production, emissions and allocation. The net allowances (allocations minus emissions) are compared for the scenarios EX, EXALTNG, EXALTG and OBA. Comparing other scenarios to OBA gives an estimation of over allocation profits (in MEAUs or M€). The difference between EXALTG and EXALTNG gives the impact of gaming. Table 2 summarises how allocations and production are obtained under each scenario.

Table 2: Scenarios

\begin{tabular}{|c|c|c|}
\hline Scenarios & Allocations & Production \\
\hline$O B A$ & $\begin{array}{c}\text { Proportional to Activity } \\
\text { (HALXALCF }<->\text { in Eq }(1))\end{array}$ & $\begin{array}{c}\text { Counterfactual } \\
\text { (explained in Section C.1) }\end{array}$ \\
\hline$E X$ & $\begin{array}{c}\text { Independent of Activity } \\
\text { (ALCF }=1 \text { in Eq (1)) }\end{array}$ & Same as OBA \\
\hline EXALTNG & $\begin{array}{c}\text { Hybrid } \\
(\text { Eq (1)) }\end{array}$ & Same as OBA \\
\hline$E X A L T G$ & Same as EXALTNG & Actual 2012 Production \\
\hline
\end{tabular}

Comparing counterfactual net exports to real net exports gives the part of the excess clinker production which is destined for clinker exports and cement exports. Assuming no stockpiling, the remaining part is attributed to the change in the clinker ratio.

\subsection{Estimation strategy}

Counterfactual values for clinker plant activity are predicted based on panel data estimations at the plant level. We use first differencing in order to control for country-level time invariant factors and the autoregressive nature of plant activity. The regression includes both country level data (cement consumption, GDP) and plant-level characteristics, such as carbon intensity, size and geographical location (coast) as detailed in Section 3.2 and in Appendix C. To assess the robustness of our results we use a semiparametric approach (Powell 1994) by specifically modelling the multiplicative error of our estimation. The counterfactual plant activity level is then not fixed but is a random variable. We perform a Monte Carlo simulation with 10,000 samples and report the average and the 95\% confidence interval.

Table 3: Data sources

\begin{tabular}{|l|l|}
\hline Variable & Source \\
\hline Emissions and HEL & European Union Transaction Log \\
\hline Clinker net exports $\left(\mathrm{NE}_{\mathrm{K}}\right)$ & $\begin{array}{l}\text { Eurostat } \\
\text { International Trade, EU Trade Since 1988 by HS2, 4, } 6 \text { and CN8 } \\
\text { Data is originally given by country pairs. Total net exports are } \\
\text { re-computed. Product category: "Cement Clinker" (252310) }\end{array}$ \\
\hline Cement net exports $\left(\mathrm{NE}_{\mathrm{C}}\right)$ & $\begin{array}{l}\text { Eurostat } \\
\text { Product category: Difference between "Cement, incl. cement } \\
\text { clinkers" (2523) and "Cement Clinker" (252310). }\end{array}$ \\
\hline Cement consumption $\left(\mathrm{C}_{\mathrm{C}}\right)$ & $\begin{array}{l}\text { 1) Cembureau (2013) for the main European countries } \\
\text { 2) VDZ for Baltic countries and Norway (Table C10). }\end{array}$ \\
\hline $\begin{array}{l}\text { Country GDP } \\
(\mathrm{GDP})\end{array}$ & $\begin{array}{l}\text { World Data Bank. } \\
\text { They are in billion current US dollars }\end{array}$ \\
\hline Clinker production $\left(\mathrm{Q}_{\mathrm{K}}\right)$ & $\begin{array}{l}\text { EUTL-derived estimation (through estimated clinker carbon } \\
\text { intensity and emissions, see A1). Where there were data gaps, } \\
\text { supplementary data were obtained from several sources e.g.: } \\
\text { - National cement association data when reliable and } \\
\text { exploitable, i.e. Oficemen (2012) for Spain }\end{array}$ \\
\hline
\end{tabular}




\begin{tabular}{|l|ll|}
\hline & $\bullet \quad$ VDZ for Germany (Table A2) \\
& $\bullet \quad \begin{array}{l}\text { Info Ciments (2013) for France } \\
\bullet\end{array}$ \\
& $\begin{array}{l}\text { Getting the Numbers Right database (GNR) for available } \\
\text { countries (UK, Italy, Poland, Czech Republic, Austria) }\end{array}$ \\
\hline
\end{tabular}

\section{Results}

\subsection{Impact of ALTs on the plant distributions}

Figure 2 displays the distribution of plant activity levels for 2012 (EXALTG), the

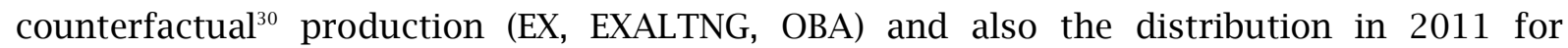
comparison. In LD countries, there is a marked jump in installations operating around the $25 \%$ and 50\% activity level thresholds in 2012, whereas the counterfactual distribution for these countries is not skewed at the thresholds. We find that in LD countries where 117 of the 246 cement installations are located, ALTs should have reduced free allocations in 50 of them, but due to gaming, only in 20 installations was they reduced in reality. Thus, in line with preliminary findings of Neuhoff et al. (2014), these results show clearly that cement companies have indeed altered plant production levels in response to ALTs rules. In MD countries, this response is noticeable but to a much less degree. The contrast between LD and MD shows the importance of the demand collapse in triggering this gaming behaviour.

Figure 2: Distribution of installations according to their activity level (approximated by E/HEL) in 2012 for observed and counterfactual production. 2012CF stands for counterfactual of 2012. Red bars indicate categories just above thresholds
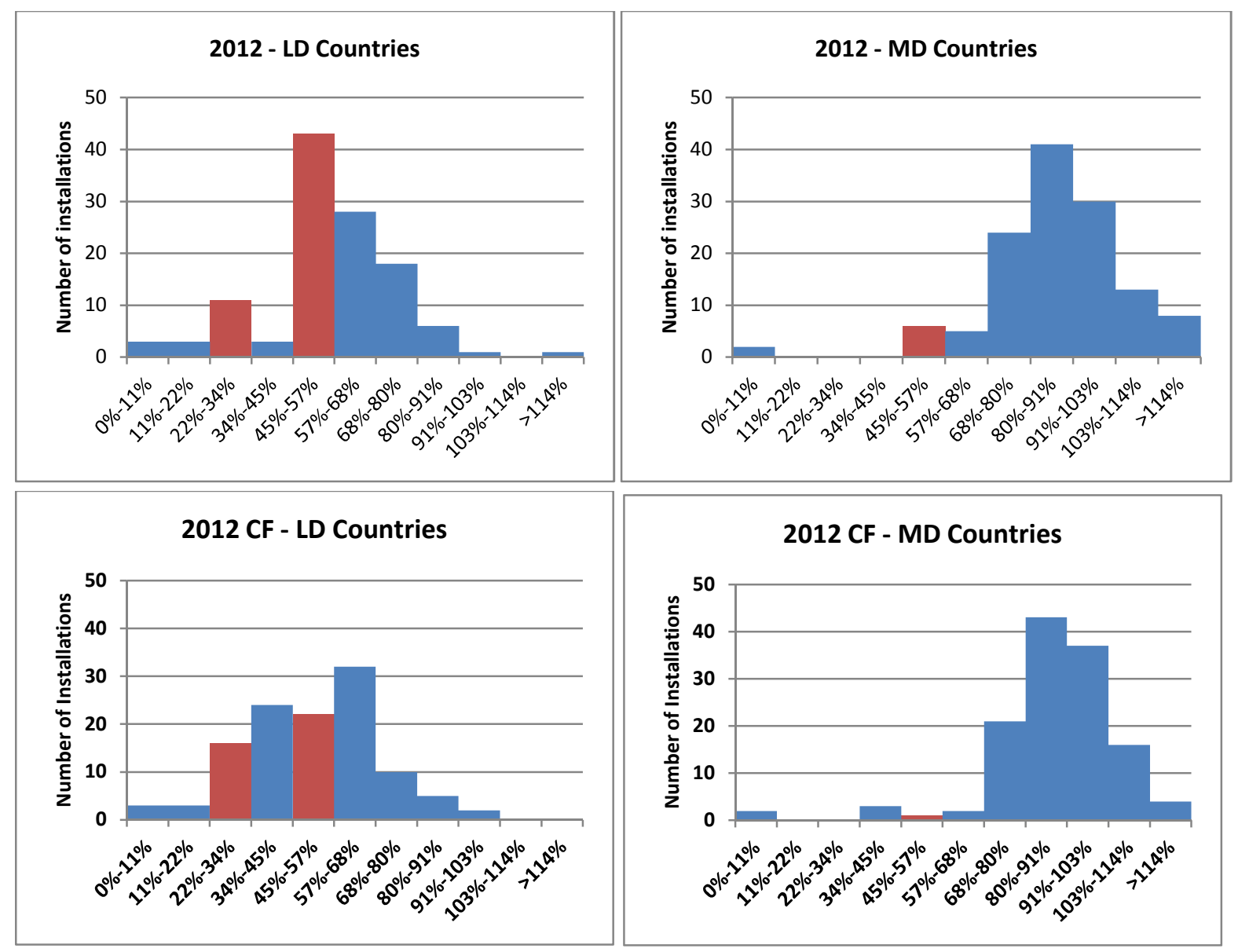

\footnotetext{
${ }^{30}$ There is not "a" but 10,000 versions of the counterfactual. The distribution displayed here corresponds to the central scenario (with average activity level for each plant).
} 

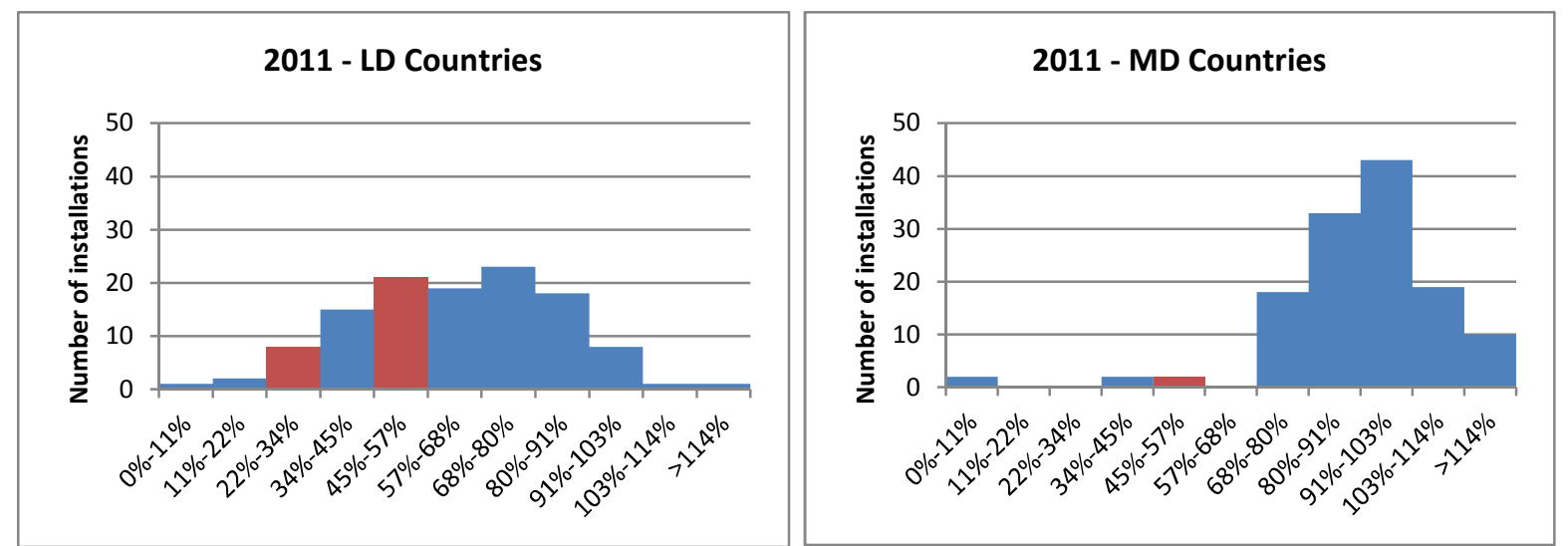

Note: An appropriate use of 2013 allocation data enables us to indirectly distinguish installations that have been in

2012 above or below thresholds (25\% and $50 \%$ of q/HAL). We find that whenever E/HEL is superior to $45 \%$ (respectively 22\%), the corresponding installation is above the first (respectively second) activity level threshold (see appendix A1 for more explanations).

\subsection{ALTs impacts on clinker production and emissions}

Table 4 gives the clinker production and the emissions for 2012 (EXALTG) and the counterfactual (EX, EXALTNG, OBA). The excess clinker production due to the introduction of thresholds rule is quantified. It represents an increase of 15\% (+7.2Mt) in LD countries, 28\% $(+3.5 \mathrm{Mt})$ for Spain and 56\% (+2.0Mt) for Greece. These increases are extremely large, even if the global impact at the EU level is more modest (5\%). The increase in the clinker production translates into increases in emissions. Altogether we estimate that an additional $5.8 \mathrm{Mt} \mathrm{CO}_{2}$ ( $+5 \%$ for the sector as a whole) have been emitted by EU cement firms as a consequence of the strategic behaviour of cement companies.

Table 4: Production and Emissions for the observed (EXALTG) and counterfactual (EX, OBA, EXALTNG) scenarios

\begin{tabular}{|c|c|c|c|c|c|}
\hline & $\begin{array}{l}\text { LD } \\
\text { countries }\end{array}$ & $\begin{array}{l}\text { MD } \\
\text { countries }\end{array}$ & $\begin{array}{l}\text { All } \\
\text { countries }\end{array}$ & Spain & Greece \\
\hline $\begin{array}{l}\text { Production (CF) in } \\
\text { Mtons }\end{array}$ & $\begin{array}{c}47.2 \\
{[45.2,49.4]}\end{array}$ & $\begin{array}{c}80.2 \\
{[76.9,83.7]}\end{array}$ & $\begin{array}{c}127.4 \\
{[123.6,131.5]}\end{array}$ & $\begin{array}{c}12.4 \\
{[11.5,13.5]}\end{array}$ & $\begin{array}{c}3.6 \\
{[3.0,4.3]}\end{array}$ \\
\hline $\begin{array}{l}\text { Production (observed) } \\
\text { in Mtons }\end{array}$ & 54.4 & 79.4 & 133.8 & 16.0 & 5.6 \\
\hline $\begin{array}{l}\text { Increased Production } \\
\text { in Mtons }\end{array}$ & $\begin{array}{c}+7.2 \\
{[5.0,9.2]} \\
p=1.00\end{array}$ & $\begin{array}{c}-0.8 \\
{[-4.2,2.5]} \\
p=0.33\end{array}$ & $\begin{array}{c}+6.4 \\
{[2.3,10.2]} \\
p=1.00\end{array}$ & $\begin{array}{c}+3.5 \\
{[2.5,4.4]} \\
p=1.00\end{array}$ & $\begin{array}{l}+2.0 \\
{[1.3,2.6]} \\
p=1.00\end{array}$ \\
\hline $\begin{array}{l}\text { Increased emissions in } \\
\text { Mtons } \mathrm{CO}_{2}\end{array}$ & $\begin{array}{c}+6.4 \\
{[4.5,8.2]} \\
p=1.00\end{array}$ & $\begin{array}{c}-0.6 \\
{[-3.6,2.2]} \\
p=0.34\end{array}$ & $\begin{array}{l}+5.8 \\
{[2.2,9.1]} \\
p=1.00\end{array}$ & $\begin{array}{c}+3.1 \\
{[2.2,3.8]} \\
p=1.00\end{array}$ & $\begin{array}{c}+1.8 \\
{[1.2,2.3]} \\
p=1.00\end{array}$ \\
\hline
\end{tabular}

Note: Reported values are the average of the 10,000 simulations and the $95 \%$ interval. $\mathrm{p}$ is the probability that the value is above zero.

\subsection{Impact of gaming on plant distribution on the free allowances}

Table 5 gives the amount of EUA's that are allocated to cement installations under the four scenarios (EX, EXALTNG, EXALTG, OBA). If installations received 100\% of their allowances regardless of their activity (i.e. the allocation under the EX scenario), then LD countries and MD countries would have received 74.5 and 70 million EUAs respectively. OBA allocations would lower allocations to 36.1 and 62.2 million EUAs respectively. The decrease in allocations is more significant for LD countries because the average activity is much lower.

Table 5: The Free Allowances (MEUAs) under the four scenarios

\begin{tabular}{|l|l|l|l|l|l|}
\hline Allocations & LD countries & MD & All countries & Spain & Greece \\
\hline
\end{tabular}




\begin{tabular}{|l|c|c|c|c|c|}
\hline & & countries & & & \\
\hline EX & 74.5 & 70.0 & 144.5 & 23.6 & 8.7 \\
\hline EXALTNG & 55.1 & 68.1 & 123.2 & 14.9 & 4.3 \\
& {$[52.8,57.3]$} & {$[67.2,68.9]$} & {$[120.8,125.6]$} & {$[13.5,16.3]$} & {$[3.5,5.1]$} \\
\hline EXALTG & 68.4 & 69.6 & 138.1 & 20.7 & 7.3 \\
(observed) & 36.1 & 62.2 & 98.2 & 9.5 & 2.7 \\
\hline OBA & {$[34.5,37.7]$} & {$[59.6,64.9]$} & {$[95.2,101.5]$} & {$[8.7,10.2]$} & {$[2.2,3.2]$} \\
\hline Allowances & +13.3 & +1.5 & +14.8 & +5.8 & +3.0 \\
Gaming Gain & {$[11.1,15.6]$} & {$[0.7,2.4]$} & $\begin{array}{c}{[12.5,17.3]} \\
\mathrm{p}=1.00\end{array}$ & $\begin{array}{c}{[4.4,7.2]} \\
\mathrm{p}=1.00\end{array}$ & {$[2.2,3.8]$} \\
$\mathrm{p}=1.00$
\end{tabular}

As explained, the scenario EXALTNG can be seen as an imperfect approximation of the OBA rule. If there had been no gaming, it would have set the allocations at 55.1 and 68.1 million EUAs. Thus for the cement sector as a whole, ALTs reduced overallocation in 2012 by 6.4 MEUSs compared to the scenario without ALTs. Had OBA been implemented instead, overallocation would have been further reduced considerably by 40 MEUAs, which corresponds to $29 \%$ of the total cement sector free allocation in 2012. The effect for the MD countries is negligible, as most of the installations have an activity level superior to $50 \%$. However for LD countries the theoretical effect of the threshold rule as an approximation of the OBA rule would have been more significant: a 50\% (that is $(74.5-55.1) /(74.5-36.1)$ ) reduction should have been obtained. With gaming (EXALTG) a reduction of only $16 \%$ prevails (that is $(74.5-68.4) /(74.5$ - 36.1)). For Spain the percentages would respectively be $61 \%$ and 20\%; and for Greece $73 \%$ and $24 \%$. Further, we estimate the allowances gaming gain at 14.8 MEUAs, located almost exclusively in LD countries, and a net gaming gain (deducing extra emissions) of 9.0 MEUAs.

\subsection{Financial potential gain associated with gaming}

In the calculation of the potential gain we assume that the increased production is sold at marginal cost, and so has no impact on profits. This gives an upper bound for the profits that could be achieved with gaming since it does not take into account the possible inefficiency costs: logistics cost for production shifting, extra sales expenditures and rebates for increased exports, opportunity cost for increasing the clinker to cement ratio). That there are inefficiency costs can be seen from the fact that not all plants achieved the $50 \%$ threshold, but some gaming was certainly worthwhile since a large proportion of plants did manage to get to the target.

To convert the increase in free allowances and the increase in emission rights into monetary value, we need to assume a $\mathrm{CO}_{2}$ price. It should be clear that the amount of profitable gaming depends on the $\mathrm{CO}_{2}$ price. We shall come back to this point in our discussion of the results. Table 6 gives the potential profit associated with gaming for a $\mathrm{CO}_{2}$ price at $7.95 € / \mathrm{t}$, which corresponds to the average future price (December 2013) during year 2012. Then it reflects more expected gains than actual gains, which may be lower or higher (the $\mathrm{CO}_{2}$ price decreased the following year, but firms may have banked these extra allowances and the $\mathrm{CO}_{2}$ price may rise in the future).

Table 6: Quantification of the monetary value of excess free allocations for the various scenarios.

\begin{tabular}{|l|l|l|l|l|l|}
\hline $\begin{array}{l}\text { Millions of } € \\
\text { relative to } \\
\text { OBA }\end{array}$ & LD countries & $\begin{array}{l}\text { MD } \\
\text { countries }\end{array}$ & All countries & Spain & Greece \\
\hline
\end{tabular}




\begin{tabular}{|l|c|c|c|c|c|}
\hline EX & 306 & 62 & 368 & 113 & 48 \\
\hline EXALTNG & {$[292,318]$} & {$[40,83]$} & {$[342,392]$} & {$[107,119]$} & {$[44,52]$} \\
& {$[145,170]$} & 49 & 207 & 50 & 13 \\
& 213 & {$[27,69]$} & {$[181,231]$} & {$[44,55]$} & {$[9,16]$} \\
\hline EXALTG & {$[209,216]$} & {$[65,67]$} & 278 & 72 & 23 \\
& {$[276,281]$} & {$[69,74]$} & {$[22,24]$} \\
\hline
\end{tabular}

Note: Reported values are the average of the 10,000 simulations and the $95 \%$ interval.

For LD countries, the potential gain of EX relative to OBA is estimated through the net increase of allowances which is $74.5-36.0 \mathrm{Mt} \mathrm{CO}_{2}$ and a EUA price $7.95 € / \mathrm{t}$ which makes 306 $\mathrm{M} €$. With the introduction of the threshold rule this increase would have been only $158 \mathrm{M} €$ had the firms not gamed the scheme. The reduction is coming from the reduced amount of free allocations due to the downfall in market demand. The gaming increases the amount of free allocations but increases emissions, bringing a potential gain at $213 \mathrm{M} €$, which represents an increase of 35\% (+55M€) relative to $158 \mathrm{M} €$. For Spain the per cent increase is $44 \%(+22 \mathrm{M} €)$ and for Greece it is $77 \%(+10 \mathrm{M} €)$. These figures are substantial even though the carbon price was low at that time. This explains why firms undertake the various inefficiencies described earlier to capture part of this gain.

\subsection{Where does the excess clinker end up? Indirect evidence revisited}

This section revisits the indirect evidence of excess clinker production proposed by Neuhoff et al. (2014). As noted, three channels have been identified, production shifting, exports increase and clinker ratio increase.

a) Production shifting in multi-plant companies. Cement company executives reported, in interviews, that subsequent to the introduction of ALTs, it was frequent practice to arrange production levels across plants to ensure being above the threshold at as many units as possible (Neuhoff et al. 2014). We observe output behaviour consistent with these statements in several cement companies which have a number of plants producing close to the thresholds. Table 7 presents four examples ${ }^{31}$. In each of these firms in 2012, production (within the same geographical country) simultaneously falls in one plant (which produced well above the threshold in 2011), and rises in another plant above the threshold (which was previously operating below the threshold).

Table 7: Evidence of within-firm-country production shifting to meet thresholds

\begin{tabular}{|c|c|c|c|}
\hline Country-Company & Installation & E/HEL 2011 & E/HEL 2012 \\
\hline Greece-W & 1 & $34 \%$ & $49 \%$ \\
Greece-W & 2 & $77 \%$ & $66 \%$ \\
Greece-W & 3 & $11 \%$ & $0 \%$ \\
\hline Spain-X & 1 & $42 \%$ & $50 \%$ \\
Spain-X & 2 & $57 \%$ & $46 \%$ \\
Spain-X & 3 & $68 \%$ & $56 \%$ \\
\hline Hungary-Y & 1 & $41 \%$ & $46 \%$ \\
Hungary-Y & 2 & $68 \%$ & $50 \%$ \\
\hline Portugal-Z & 1 & $34 \%$ & $64 \%$ \\
Portugal-Z & 2 & $55 \%$ & $51 \%$ \\
Portugal-Z & 3 & $71 \%$ & $60 \%$ \\
\hline
\end{tabular}

Note: An appropriate use of 2013 allocation data enables us to indirectly distinguish installations that have been in 2012 above or below thresholds ( $25 \%$ and $50 \%$ of q/HAL). We find that whenever E/HEL is superior to $45 \%$ (respectively 22\%), the corresponding installation is above the first (respectively second) activity level threshold (see appendix A1 for more explanations).

\footnotetext{
${ }^{31}$ We only display here groups of installations belonging to a country-company that are the most consistent with production shifting, but avoid cherry-picking individual installations. For the four cases, all installations of a certain country-company are displayed.
} 
b) Exports. Table 8 gives net exports of clinker and clinker embedded in cement from 2010 to 2012 for LD and MD countries. We observe a surge in clinker net exports in LD countries: 6.21 Mt in 2012, compared to $2.03 \mathrm{Mt}$ and $1.94 \mathrm{Mt}$ in 2010 and 2011 respectively. In contrast MD countries remained small net importers of clinker and no significant shift was observed in their trade patterns. Further analysis revealed that these clinker exports in 2012 were destined mainly to countries in Latin America and Africa, including Brazil, Togo, Ghana, Cameroon, Côte d'Ivoire, and Mauritania and Nigeria.

Table 8: Clinker net exports in 2010, 2011 and 2012 in LD and MD countries in millions of tonnes

\begin{tabular}{|c|c|c|c|}
\hline LD Countries & $\mathbf{2 0 1 0}$ & $\mathbf{2 0 1 1}$ & $\mathbf{2 0 1 2}$ \\
\hline Clinker & 2.03 & 1.94 & 6.21 \\
\hline Clinker in Cement & 5.49 & 4.58 & 6.37 \\
\hline
\end{tabular}

\begin{tabular}{|c|c|c|c|}
\hline MD Countries & $\mathbf{2 0 1 0}$ & $\mathbf{2 0 1 1}$ & $\mathbf{2 0 1 2}$ \\
\hline Clinker & -0.93 & -0.74 & -0.71 \\
\hline Clinker in Cement & 2.24 & 2.46 & 2.02 \\
\hline
\end{tabular}

Note: Source: Eurostat we use a common clinker ratio of $75 \%$ to compute clinker embedded in cement.

c) Clinker ratio. Another way excess clinker production might materialise is in a higher clinker-to-cement ratio. That is, firms could use more clinker to produce the same ton of cement. The clinker ratio can be recomputed at the macro level (state of group of states) with the formula $R=\frac{Q_{K-N E_{K}}}{C_{C}+N E_{C}}$, where $Q_{K}$ is the clinker production, $N E_{K}$ and $N E_{C}$ net exports of clinker and cement, and $C_{C}$ the cement consumption (see Appendix B for explanation and Table 3 for data source). Table 9 shows the clinker ratio for the MD countries, LD countries, Spain and Greece. There is some suggestion that the historically declining trend in the clinker-to-cement ratio reversed in 2012, notably in Spain and Greece.

Table 9: Clinker-to-Cement Ratio in selected areas (source: authors' analysis)

\begin{tabular}{|l|r|r|r|}
\hline Clinker Ratio & $\mathbf{2 0 1 0}$ & $\mathbf{2 0 1 1}$ & $\mathbf{2 0 1 2}$ \\
\hline MD Countries & $76 \%$ & $76 \%$ & $77 \%$ \\
\hline LD Countries & $74 \%$ & $72 \%$ & $74 \%$ \\
\hline Spain & $79 \%$ & $76 \%$ & $82 \%$ \\
\hline Greece & $76 \%$ & $71 \%$ & $75 \%$ \\
\hline
\end{tabular}

\subsection{Decomposing the channels for clinker disposal}

In order to understand better the effects of the distortions that arise from ALTs, we attempt to decompose the excess clinker output ${ }^{32}$ into the main destinations to which they are channelled through: changes to clinker ratio of domestic cement and increase in exports (clinker or cement). Although it is likely that there is some stockpiling, the lack of data makes it difficult to attribute excess production to this channel.

This decomposition requires that actual net export volumes of cement and clinker are compared to counterfactuals levels (see Appendix C.2 for the estimation method and data used). Assuming no stockpiling, we can attribute the remaining excess clinker output to clinker ratio increase. Table 10 gives the results. Figure 3 provides a graphical representation. For LD countries, net exports of clinker increased by 6.2 Mt while our counterfactual is $4.6 \mathrm{Mt}(+1.6 \mathrm{Mt})$; the net export of cement increased by $8.5 \mathrm{Mt}$ while the counterfactual is $6.1 \mathrm{Mt}(+1.7 \mathrm{Mt}$ of clinker embedded); this implies that $2.4 \mathrm{Mt}$ of clinker

\footnotetext{
${ }^{32}$ Production shifting in multiplant companies does not generate excess clinker output, hence is not quantitatively assessed.
} 
went into the increased content of clinker in cement. This latter figure represents an increase of $6 \%$ relative to our counterfactual for the clinker to cement ratio as defined in the previous section. The values of clinker ratio effect are higher here than the estimates in Section 4.6 suggesting that stockpiling of excess clinker output may be occurring, as well as increased clinker ratio of cement exports.

Figure 3: Routes of excess clinker production decomposition

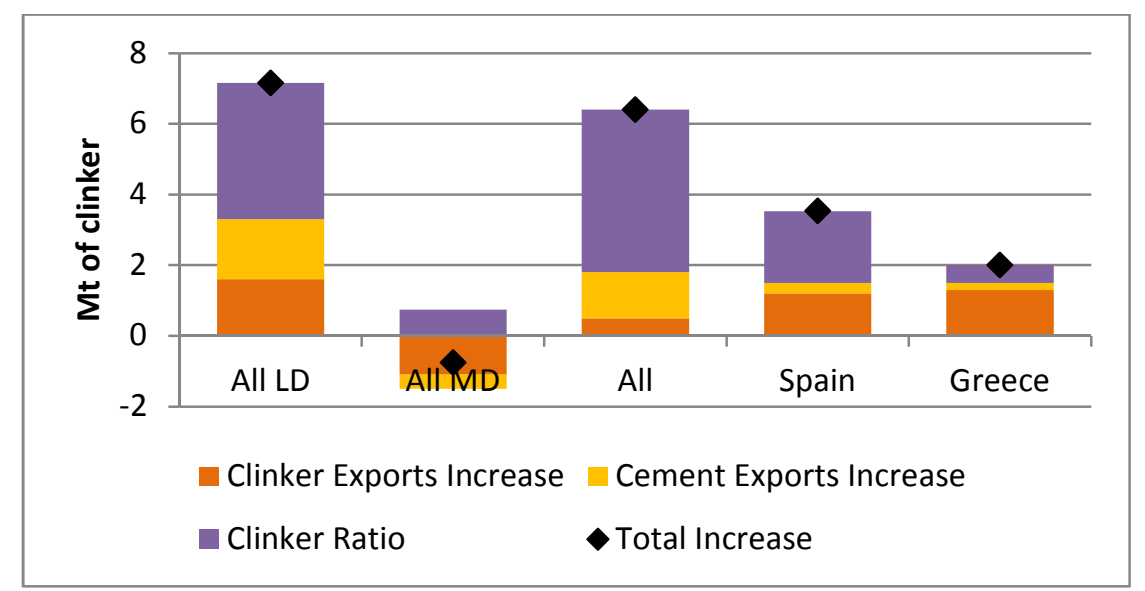

Table 10: Real and counterfactual net exports of clinker and cement (Mt)

\begin{tabular}{|c|c|c|c|c|c|c|c|c|c|}
\hline & $\begin{array}{l}\text { Total } \\
\text { Increase }\end{array}$ & Clir & $\begin{array}{r}2012 \\
\text { er Net }\end{array}$ & xports & Cem & $\begin{array}{r}2012 \\
\text { nt Net }\end{array}$ & xports & Clin & er Ratio \\
\hline Region & $\begin{array}{l}\text { Production } \\
\text { Clinker }\end{array}$ & $\mathrm{CF}$ & $\begin{array}{c}\text { Obse } \\
\text { rved }\end{array}$ & Diff & $\mathrm{CF}$ & $\begin{array}{l}\begin{array}{l}\text { Obse } \\
\text { rved }\end{array} \\
\end{array}$ & Diff* $\mathrm{R}$ & Effect & Relative \\
\hline All LD & 7.2 & 4.6 & 6.2 & +1.6 & 6.1 & 8.5 & +1.7 & 3.9 & $+6 \%$ \\
\hline All MD & -0.8 & 0.4 & -0.7 & -1.1 & 3.3 & 2.7 & -0.4 & 0.7 & $+1 \%$ \\
\hline All & 6.4 & 5.0 & 5.5 & +0.5 & 9.4 & 11.2 & +1.3 & 4.6 & $+3 \%$ \\
\hline Spain & 3.5 & 2.2 & 3.4 & +1.2 & 2.2 & 2.6 & +0.3 & 2.0 & $+12 \%$ \\
\hline Greece & 2.0 & 0.5 & 1.8 & +1.3 & 1.5 & 1.7 & +0.2 & 0.5 & $+9 \%$ \\
\hline
\end{tabular}

\subsection{Robustness and caveats}

In this section we briefly discuss how our results would be affected if we were to relax hypotheses $H_{1}, H_{2}$, and $H_{3}$. Let us briefly recall these assumptions which may be seen as behavioural rules reflecting the anecdotal evidence.

Hypothesis $H_{1}$ : the cement market (quantity and price) is identical for OBA, and EX/EXALTNG Hypothesis $\mathrm{H}_{2}$ : the cement market (quantity and price)for EXALTG is identical to the one of EX/EXALTNG

Hypothesis $\mathrm{H}_{3}$ : The increased production due to gaming is sold at marginal cost (excluding emission cost), and so has no impact on profits

We now detail the potential impact of adopting more standard hypotheses regarding profit maximizing behaviour. A change in the allocation rule will impact the cement market (quantity and price) and the trade flows (leakage). ALT rules need also be analysed in terms of profit maximizing. Qualitatively we certainly expect that going from EX to OBA would increase the domestic consumption, increase domestic production, decrease the output price and reduce net imports. It would of course eliminate the lump sum profits due to the free allocation grandfathering rule. Going from EX to EXALTNG would only matter in terms of decreasing these lump sum profits. Now going to EXALTG would partly reduce the revised 
differences between EX and OBA as regards the domestic consumption, the domestic production, the output price and the trade flows. We can expect this because the reduction in domestic production would be partly offset by the excess production to achieve the thresholds at some plants, part of this excess production affecting the domestic market and the trade flows. We have neither the model nor the data to quantify how this change in hypotheses would quantitatively affect our results.

Fowlie et al. (2012) provide some ideas on how this could be done. They analyze the impact of various allocation schemes in the context of the US cement industry. Their model incorporates two modelling features: short term oligopolistic Cournot competition with endogenous capacity constraints and leakage (imports are introduced through a competitive fringe). The model is dynamic with incumbents and entrants, and allows for investment strategies. Firms maximize their discounted profits. The model is calibrated on a regional basis (US districts; areas roughly equivalent to EU member states) and then analyzed under various hypothetical scenarios.

Among other results they point out differences between OBA, grandfathering (EX) and grandfathering with closure rule (a weak version of EXALTG in which free allocations are lost if the plant is closed). As expected, the cement market and the trade flows differ between OBA and grandfathering, the latter leads to lower domestic production and more leakage. The difference in profits depends on the level of the lump sum transfer associated with free allocations. The novel part of their analysis (the standard economic literature on OBA reported in the introduction assumes a static framework) concerns the difference between grandfathering and grandfathering with a closure rule, the latter increases domestic production and reduces leakage, at least temporarily. The introduction of the closing rule induces some gaming (excess domestic production relative to EX), which is beneficial to the incumbents.

It would certainly be interesting to use a similar approach to quantify how our results would be affected if $H_{1}, H_{2}$, and $H_{3}$ were replaced by more standard economic assumptions based on explicit profit maximizing. This may be particularly important in a context of high carbon price since this may trigger more economic behaviour than the one we assumed. Still our intuition is that the qualitative insights mentioned above would hold. This needs to be confirmed by further work.

\section{Conclusions and policy options}

An important change in the EU-ETS phase 3 for EITE concerns the introduction of the activity level threshold rule (ALTs). The underlying rationale for its introduction is that it would reduce the overallocation profits in case of downfall in the demand: whenever the activity level of an installation falls below some threshold (50\%, 25\%, 10\%), relative to its historic activity level used to allocate free allocations, the allocation would be reduced accordingly (50\%, 25\%, 0\%).

Our ex post analysis of year 2012, the first year in which the threshold rule applies, focused on the cement sector, a sector in which approximately half the EU countries had experienced a significant downfall in consumption (LD countries). It provides a natural experiment to evaluate the consequences of this rule.

Our main conclusion is that while ALTs did reduce to some extent overallocation profits, they also created operational distortions which lead to outcomes inconsistent with the low carbon transition of EU energy intensive industries. The reduction in overallocation profits is less than expected because of the gaming behaviour of the industry to achieve the thresholds, during periods of low market demand. Thanks to the elaboration of a 
counterfactual, we have been able to quantify that after the introduction of ALTs: the potential overallocation profit with gaming is $278 \mathrm{M} €$ ( $2 € / \mathrm{t}$ clinker) and $207 \mathrm{M} €$ without gaming, while it would have been $368 \mathrm{M} €$ in the absence of ALTs. The expected reduction in windfall profits due to the ALTs is $44 \%$ while the actual reduction is $24 \%$. The incentives are magnified in low demand countries, where profit with gaming is $213 \mathrm{M} €$ (3.9 $€ /$ t clinker) and $158 \mathrm{M} €$ without gaming, while it would have been $306 \mathrm{M} €$ without ALTs. We examined three ways in which firms' operations are altered in response to ALTs: shifting production among plants; increasing net exports of clinker and cement; increasing the clinker to cement ratio.

In the 2000's top management attention to the issues of climate change emerged as an important dimension of corporate social responsibility and a large number of companies got involved in proactive strategies to limit their own emissions (Arjalies Goubet and Ponssard 2013). The EU-ETS positively contributed to turn this strategy into operational practice by putting a price on carbon. The distortions reported in our study are particularly detrimental in this respect: If the threshold is not achieved in a given plant this encourages the firm to increase its production to obtain a lump sum gain in free allowances. The cement industry has several ways to get rid of this excess production without incurring significant incremental costs on top of the induced emission costs. It can reshuffle the production load at close-by plants. It can increase the level of clinker in cement. It can also increase its exports to external markets. All of this is at the detriment of the global corporate strategy to pursue a low carbon transformation of the sector. Our study demonstrates that these effects are substantial.

Our results have been obtained in a context of low carbon price, severe downfall in market demand, and large allocations of free allowances. However, a higher carbon price would make our results even more relevant; the higher the carbon price the higher the incentive to achieve the thresholds. ${ }^{33}$ Had we observed growth, the threshold rule may have been less relevant. Anecdotal evidence ${ }^{34}$ suggests that instead, the reserve for new entrants may have been a more important source of distortions (there would be an incentive to have an artificially high production level during the period used to fix the equivalent of HAL for new entrants).

These considerations suggest that the activity level thresholds may need to be reconsidered for sectors such as cement for which carbon costs represent a significant share of production costs. This raises the question of what to put in their place instead. As mentioned in the introduction, economists generally agree that in the absence of global carbon prices, replacing free allocation with full auctioning and using border carbon adjustments offers the most efficient solution. This is because it helps in levelling the carbon costs between domestic and foreign producers while also allowing for carbon costs to be passed along the value chain to incentivise demand side abatement. Politically this solution has not yet gained serious traction. This is largely due to concerns that borderlevelling may be perceived as protectionism disguised as environmentalism and hence not conducive to building trust in international climate negotiations. However, the situation may change. If one looks forward to the post-2020 period, a larger number of nations are expected to have begun implementing carbon prices. More countries will face similar challenges related to designing appropriate anti-leakage measures that the EU now faces and thus there may be more scope for cooperative approaches. Border-levelling via international

\footnotetext{
${ }^{33}$ Take a EUA price at $20 € / \mathrm{t}$ a simple extrapolation for LD countries would bring up the potential wind fall profit to $236 * 20 / 9=524 \mathrm{M} €$. However if we assume that all plants achieve the 50\% threshold, a reasonable assumption for a EUA price at $20 € / \mathrm{t}$, it would go up to $583 \mathrm{M} €$. The expected reduction remains at $42 \%$ but the actual one drops to $22 \%$. Note however that a high carbon cost might endanger the validity of assumption $H_{1}$ and could possibly lead to a result in which EXALTG would be preferred to EX, but still worse than OBA.

${ }^{34}$ Ref. private conversation with industry representatives.
} 
cooperation would, however, take time to negotiate and design. This raises the question as to the interim solution.

One option is to increase the number of activity level thresholds to reduce the incentive to game output. For example, a threshold at 50\%, $60 \%$ and $70 \%$ for cement may incentivise a larger number of installations to increase their clinker production to the next highest threshold. Since thresholds create an allocation system that falls between an ex-ante and an ex-post scheme, it would be much simpler to implement full output-based allocation for sectors like cement, where the risk of distortions arising is high, because carbon costs are high relative to production costs in the absence of free allocation. The analysis in this paper suggests that this option would outperform both ex ante allocation with and without thresholds in terms of reducing distortions and over allocation profits.

However, a number of issues must be carefully considered before going in that direction. A central drawback of a move to OBA is that little can be expected in terms of carbon price pass-through to product prices and hence demand side substitution towards lower-carbon goods. For sectors where carbon costs are high as a share of production costs, such as cement, this would significantly limit the EU's potential to reduce emissions cost-effectively and to decarbonise these sectors. Unlike ex ante allocation, OBA implies the loss of an absolute cap for free allocations and this may be politically contentious point. Further, the implementation of OBA to selected sectors may also raise political difficulties. There are ongoing discussions on how to circumvent these issues. For example the loss of demand side substitution incentives could perhaps be restored with a consumption charge on downstream products (Neuhoff et al. 2014). Output based scheme with hybrid benchmark has been implemented in California in 2012. An ex post study on this implementation would be welcome to see if, again, the devil lies in the detail.

\section{Acknowledgements}

The authors wish to acknowledge the following people for their helpful comments and suggestions in the writing of this paper: Philippe Quirion, Andrei Marcu, Karsten Neuhoff, Bruno Vanderborght, Luca Taschini, Catherine Thomas, DG Clima and the maintainers of the EUTL public registry, WBCSD and all the people who contribute to the Getting the numbers right (GNR) cement sector database and numerous people from the cement industry. JeanPierre Ponssard gratefully acknowledges the financial support from the ANR/Investissements d'avenir (ANR -11- IDEX-0003-02). Misato Sato gratefully acknowledges financial support from European Community's Seventh Framework Programme under Grant Agreement No. 308481 (ENTRACTE) the Grantham Foundation and the ESRC through the Centre for Climate Change Economics and Policy.

\section{References}

Arjaliès, Diane L., Goubet Cécile, and Ponssard Jean P. 2013. Strategic Approaches of CO2 Emissions: The Cases of the Cement Industry and Chemical Industry. http://papers.ssrn.com/sol3/papers.cfm?abstract_id=2287784

Boyer, Marcel, and Ponssard Jean P. 2013. Economic Analysis of the European Cement Industry. Working paper (Scientific Publication) no. 2013s-47, CIRANO.

Branger, Frédéric, and Philippe Quirion. 2015. "Reaping the Carbon Rent: Abatement and Overallocation Profits in the European Cement Industry, Insights from an LMDI 
Decomposition Analysis.” Energy Economics 47 (January 2015): 189-205. doi:10.1016/j.eneco.2014.11.008.

California Air Resources Board. 2013. California Cap on Greenhouse Gas. Emissions and Market-Based Compliance Mechanisms. Air Resources Board.

CEMBUREAU. 2013. World Statistical Review 2001 - 2011. CEMBUREAU. http://www.cembureau.eu/world-statistical-review-1996-2008-0

Demailly, Damien, and Quirion Philippe. 2006. CO abatement, competitiveness and leakage in the European cement industry under the EU ETS: grandfathering versus output-based allocation. Climate Policy 6:93-113.

Duan, Naihua. 1983. Smearing Estimate: A Nonparametric Retransformation Method. Journal of the American Statistical Association 78(383): 605-610.

Ellerman, Denny A., Joskow Paul L., Richard Schmalensee, Montero Juan P., and Elizabeth, Bailey M. 2000. Markets for Clean Air: The U.S. Acid Rain Program. Cambridge, United Kingdom: Cambridge University Press.

Ellerman, Denny A. 2008. New entrant and closure provisions: how do they distort? The Energy Journal 29:63-76.

European Union Transaction Log. European Commission. http://ec.europa.eu/environment/ets/napMgt.do

European Commission. 2011. Decision 2011/278/EU on determining Union-wide rules for harmonised free emission allowances pursuant to Article 10a of Directive 2003/87/EC, European Commission, Brussels. http://eur-lex.europa.eu/legalcontent/EN/TXT/PDF/?uri=OJ:L:2011:130:FULL\&from=EN

Eurostat http://epp.eurostat.ec.europa.eu/newxtweb/setupdimselection.do\#

Fischer, Carolyn and Fox Alan. 2007. Output-based allocation of emissions permits for mitigating tax and trade interactions. Land Economics 83, no. 4: 575-599.

Fischer, Carolyn, and Fox Alan. 2012. Comparing policies to combat emissions leakage: Border carbon adjustments versus rebates, Journal of Environmental Economics and Management 64, no. 2: 199-216.

Fowlie, Meredith, Reguant,Mar, and Ryan Stephen P. Forthcoming. Market-based emissions regulation and industry dynamics. Journal of Political Economy.

Hepburn, Cameron, Grubb Michael, Neuhoff Karsten, Matthes Felix, and Tse Max. 2006. Auctioning of EU ETS phase II allowances: How and why? Climate Policy 6, no.1:137-160.

Horowitz, Joel L., and Marianthi Markatou. 1996. "Semiparametric Estimation of Regression Models for Panel Data.” The Review of Economic Studies 63, no. 1 (January 1, 1996): 145-68. doi:10.2307/2298119.

Hourcade, Jean C., Demailly Damien, Neuhoff Karsten, and Misato Sato. 2007. Differentiation and dynamics of EU-ETS competitiveness impacts. Climate Strategies report

GOV.UK. 2014. Aggregates, cement and ready-mix concrete market investigation. https://www.gov.uk/cma-cases/aggregates-cement-and-ready-mix-concrete-marketinvestigation

Jefferies 2012 Building materials. International Equity Research, August.

Jensen, Michael C. 2003. Paying People to Lie: The Truth About the Budgeting Process. European Financial Management 9, no. 3:379-406. 
Info Ciments. 2013. Statistiques de l' Industrie Cimentiere Francaise.

http://www.infociments.fr/publications/industrie-cimentiere/statistiques/st-g08-2012,

Laing, Timothy, Sato Misato, Grubb Michael, and Comberti Claudia. 2014. The effects and side-effects of the EU emissions trading scheme. WIREs Clim Change 5:509-519.

Locke, Edwin A. 2001. Motivation by goal setting. In Golembiewski, R. T. (ed.), Handbook of Organizational Behavior. New York: Marcel Dekker.

McKinsey\&Company. 2008. Pathways to a Low Carbon Economy: Version 2 of the Global Greenhouse Gas Abatement Curve. McKinsey\&Company.

Meunier, Guy, Ponssard Jean P., and Quirion Philippe. 2014. Carbon leakage and capacitybased allocations: Is the EU right? Journal of Environmental Economics and Management 68, no. 2: 262-279.

Monjon, Stephanie, and Quirion Philippe. 2011. Addressing leakage in the EU ETS: Border adjustment or output-based allocation? Ecological Economics 70, no.11:1957-1971.

Neuhoff, Karsten, Vanderborght Bruno, Ancygier Andrzej Atasoy Ayse T., Haussner Manuel, Ismer Roland, Mack Bendict, Sabio Nagore, Ponssard Jean P., Quirion Philippe, van Rooij Arjan, Sartor Oliver, Sato Misato, and Shopp Anne. 2014. Carbon control and competitiveness post 2020: The cement report, Climate Strategies, 2014, London. February 2014.

Neuhoff, Karsten, Keats Kim, and Sato Misato. 2006. Allocation, incentives and distortions: the impact of EU ETS emissions allowance allocations to the electricity sector. Climate Policy 6, no. 1:73-91.

Oficemen. 2013. Anuario del sector cementero español. 2012. Oficemen, Agrupacion de fabricantes de cemento de Espana.

https://www.oficemen.com/Uploads/docs/Anuario\%202012\%281\%29.pdf

Pahle, Michael, Fan Lin, and Schill Wolf P. 2011. How emission certificate allocations distort fossil investments: The German example. Energy Policy 39, no. 4:1975-1987.

Powell, James L. "Chapter 41 Estimation of Semiparametric Models.” In Handbook of Econometrics, edited by Robert F. Engle and Daniel L. McFadden, 4:2443-2521. Elsevier, 1994. http://www.sciencedirect.com/science/article/pii/S1573441205800108.

Quirion, Philippe. 2009. Historic versus output-based allocation of GHG tradable allowances: a survey. Climate Policy 9:575-592.

Sallee, James M., and Slemrod Joel. 2012. Car notches: Strategic automaker responses to fuel economy policy. Journal of Public Economics 96, no. (11-12):981-999.

Sandbag. 2011. Carbon Fat Cats 2011: The Companies profiting from the EU Emissions Trading Scheme. Report, Sandbag Climate Campaign.

Sartor, Oliver, Pallière Clement, and Lecourt Stephen. 2014. Benchmark-based allocations in EU ETS Phase 3: an early assessment, Climate Policy 14, no. 4:507-524.

VDZ. Facts and Figures - Cement Sales and Consumption. http://www.vdzonline.de/en/publications/factsandfigures/cement-sales-and-consumption/

Wooldridge, Jeffrey. M., 2010. Econometric analysis of cross section and panel data. MIT press.

The World Bank. 2015 World Development Indicators

http://databank.worldbank.org/data/views/variableselection/selectvariables.aspx?source $=W$ orld-Development-Indicators 
World Business Council for Sustainable Development (WBCSD). 2014. Getting the Numbers Right database, Cement Sustainability Initiative. http://wbcsdcement.org/GNR-

2012/index.htmlhttp://wbcsdcement.org/GNR-2012/index.html

\section{Appendix}

\section{A. EUTL Data computations}

\section{A.1 Determination of the Activity Level Correction Factor $\left(\mathrm{ALCF}_{2013}\right)$ at the plant level}

The key challenge is to correctly distinguish installations that are above or below thresholds ( $25 \%$ and $50 \%$ of $\mathrm{q} / \mathrm{HAL}$ ), despite the limitation that activity levels have to be approximated using emissions data (E/HEL). To do so, we exploit the observations from the 2013 allocation data, which revealed whether or not the installation had seen its allocation reduced because its 2012 activity level fell below a threshold. Allocations in 2013 are equal to (cf equation (1)):

$$
A_{i, 2013}=C S C F_{2013} \times I_{B} \times H A L_{i} \times A L C F_{i, 2013}
$$

Where $\operatorname{CSCF}_{2013}$ is the 2013 Cross Sectoral Correction Factor (0.9427), $I_{B}$ the clinker carbon intensity benchmark (766 kg CO 2 per ton of clinker), and $H A L_{i}$ the Historical Activity Level of installation $i$ (in tons of clinker). Transforming the previous equation, where both $H A L_{i}$ and $A L C F_{i, 2013}$ are unknown, we obtain:

$$
\frac{\operatorname{CSCF}_{2013} \times \frac{I_{B}}{I_{A}} \times H E L_{i}}{A_{i, 2013}}=\frac{1}{A L C F_{i, 2013}} \times \frac{I_{i, H A L}}{I_{A}}
$$

Noting $I_{i, H A L}=\frac{H E L_{i}}{H A L_{i}}$ (corresponding approximately to the clinker carbon intensity for the HAL producing years), and $I_{A}$ is the average clinker carbon intensity (863 $\mathrm{kg} \mathrm{CO}$ per ton of clinker, GNR, indicator 321) in 2008.

The ratio at the left part of the equation can be computed with available data. On the right part, we have $A L C F_{i, 2013}$, which we want to find, and the ratio, $\frac{I_{i, H A L}}{I_{A}}$, which is unknown as well but bounded and likely to be close to 1 . Indeed, $I_{i, H A L}$ varies in an extreme range from $720 \mathrm{~kg}$ $\mathrm{CO}_{2}$ per ton of clinker to $1300 \mathrm{~kg} \mathrm{CO}_{2}$ per ton of clinker (and for the very large majority of the plants from 780 to $950 \mathrm{~kg} \mathrm{CO}$ per ton of clinker), which translates into a ratio $\frac{I_{i, H A L}}{I_{A}}$ varying from 0.83 to 1.51 (and most likely from 0.90 to 1.10). Then, if the ratio, is comprised between 0.83 to 1.51 (respectively between 1.67 and 3.01, and between 2.64 and $4.80^{35}$ ), we infer that $A L C F_{i, 2013}=1$, (respectively 0.5 and 0.25 ).

This enabled catching out situations in which imperfections in the E/HEL measure as a proxy for the q/HAL would have led to a false conclusion about whether an installation was truly above or below its activity threshold in 2012. We found that the actual thresholds for the E/HEL measure that matched the 2013 allocation data were slightly lower in practice, at 22\% and at $45 \%$, rather than $25 \%$ and $50 \%$. Discussion with industry experts revealed that there was a logical explanation for this systematic bias: clinker producers often have more than one kiln inside an installation that is treated as a single unit for free allocation purposes. When demand falls, it is common to concentrate production in the most efficient kiln(s).

\footnotetext{
${ }^{35}$ In our data there is actually a gap between 2.14 and 4.01 so no case of overlapping.
} 
Thus emissions may fall by slightly more than overall clinker production, creating a slight downward bias in E/HEL as a measure of q/HAL in low demand countries. This bias could also be explained by the clinker carbon intensity improvement between HAL years and 2012 or to the fact that it is the responsibility of the company to report to the authorities if it is producing under the threshold. ${ }^{36}$

\section{A.2 Determination of clinker carbon intensity and production at the plant level}

Once the $A L C F_{i, 2013}$ has been determined at the plant level $i$ (see previous section), the plant clinker carbon intensity for HAL years, $I_{i, H A L}$, can then be obtained with the previous equation.

For 20 plants (out of 246), we found an unusual number (below $700 \mathrm{~kg} \mathrm{CO}$ per ton of clinker), possibly due to a capacity increase, and put instead a default value equal to $I_{A}$.We also set the default value $I_{A}$ when $A_{i, 2013}=0$ (meaning $A L C F_{i, 2013}=0$ or plant closure), making the computation impossible (15 plants).

We then correct the first approximation of clinker carbon intensity so as weighted average $\mathrm{e}^{37}$ clinker carbon intensity in big countries corresponds to GNR data in 2008 (818, 831, 832, $797,847,858,849$ and $842 \mathrm{~kg} \mathrm{CO}$ per ton of clinker for respectively Austria, Czech Republic, France, Germany, Italy, Poland, Spain and the United Kingdom). Finally we correct values of clinker carbon intensity in plants of other countries in the same way, so as the European weighted average clinker carbon intensity $\left(I_{A}\right)$.

Once clinker carbon intensity is estimated for each plant, clinker production can be obtained through emissions $\left(Q_{K, i, t}=E_{i, t} \times I_{i, H A L}\right.$, $)$. We assume that clinker carbon intensity does not evolve over time.

\section{B. Macro data consistency at the national level}

If we denote the six different variables:

- $\mathrm{Q}_{\mathrm{K}}$ clinker production

- $\mathrm{Q}_{\mathrm{C}}$ total cement production

- $\mathrm{NE}_{\mathrm{K}}$ clinker net exports

- $\quad \mathrm{NE}_{\mathrm{C}}^{\mathrm{K}}$ cement net exports

- $\mathrm{C}_{\mathrm{c}}$ cement consumption

- $\quad \mathrm{R}$ clinker-to-cement ratio

We have two equations translating the conservation of cement on the one hand and the conservation of clinker on the other hand (neglecting stockpiling):

$$
\begin{gathered}
Q_{C}=C_{C}+N E_{C} \\
Q_{K}=R \times Q_{C}+N E_{K}
\end{gathered}
$$

These equations must be verified for each country every year (for real of counterfactual scenario).

In this paper for real data, $\mathrm{Q}_{\mathrm{K}}, \mathrm{NE}_{\mathrm{K}}, \mathrm{NE}_{\mathrm{C}}$ and $\mathrm{C}_{\mathrm{C}}$ are obtained through different sources (see Table $\mathrm{X}$ ), and $\mathrm{Q}_{\mathrm{C}}$ and $\mathrm{R}$ are re-computed (we have $R=\frac{Q_{K-N E_{K}}}{C_{C}+N E_{C}}$.

\footnotetext{
${ }^{36}$ At least in France, ref private conversation with a policy-maker.

37 The Weights are production, as multiplying plant emissions by this first approximation of clinker carbon intensity gives a first approximation of clinker production at the plant level $\left(\tilde{Q}_{K, i, 2008}=I_{i, H A L} \times E_{i, 2008}\right)$.
} 


\section{Counterfactual clinker production and net trade estimations}

\section{C1. Plant level clinker production estimation}

We calculate counterfactual clinker production levels of a plant in 2012 and characterise output behaviour of firms conditional on national and plant level variables. As noted, the unobserved level activity of plant $i$ in year $t$ is approximated by the observed level of emissions PlantActivity $y_{i, t} \approx \frac{E_{i, t}}{H E L_{i}}$ the activity level of plant $i$ in year $t$ (ratio of emissions divided by historic emissions level). As noted also, we assume that cement consumption is independent of allocation rules. Therefore, cement consumption would have been the same in 2012 had the ALTs rule not been implemented.

We use a multiplicative panel data model to estimate the following specification of clinker production level in plant $i$ at time $t$ to obtain parameters used to calculate counterfactual activity level in 2012:

$$
\begin{aligned}
\Delta \ln \text { PlantActivity }_{i, t}=\alpha_{0} & +\beta_{1} \Delta \text { InCementConsum }_{c \ni i, t}+\beta_{2} \Delta \ln \text { GDP }_{c \ni i, t}+\gamma_{1} \text { InRelativeCo2intensity }_{i} \\
& +\gamma_{2} \text { lnRelativePlantsize }_{i}+\gamma_{3} \text { Coast }_{i}+\varepsilon_{i t}
\end{aligned}
$$

In order to accommodate the autoregressive nature of plant activity, we define all countrylevel variables (source of the data is in Table 3) including the dependent variable in first differenced terms. This allows us to difference out the time-invariant country specific heterogeneity, using adjacent observations. The dependent variable is the (first differenced) natural $\log$ of the activity level of plant $i$ in year $t$. Cement consumption and GDP are also expressed in first differenced natural log terms. In addition, we include time invariant plantlevel variables: the relative average carbon intensity of a plant ${ }^{38}$; relative plant $\operatorname{size}^{39}$; and a dummy variables for coastal plants. ${ }^{40}$ In order to minimize measurement errors which would bias the regression, we regroup some small countries into larger entities which are coherent in terms of regional market: Baltic countries, Benelux, Norway-Sweden and Slovenia-Italy. As the Breush-Pagan test reveals the presence of heteroskedasticity,robust standard errors clustered at the country level are used.

Table 12: Regression results of corrections at the plant level

\begin{tabular}{lc}
\hline & $(1)$ \\
\hline Log Cement & $0.819^{* * * *}$ \\
Consumption & $(7.23)$ \\
Log GDP & 0.235 \\
& $(1.31)$ \\
Log Relative Carbon & $-0.333^{* * * *}$ \\
Intensity & $(3.05)$ \\
& \\
Log Relative & 0.013 \\
Historical Activity & $(1.10)$ \\
Level & \\
Coastal dummy & $-0.037^{* * * *}$
\end{tabular}

\footnotetext{
${ }^{38}$ The relative carbon intensity is defined as the natural log of carbon intensity at the plant level divided by the average carbon intensity in the country it is located (RelativeCo2intensity ${ }_{i}=\ln \left(I_{H A L, i} / \overline{I_{H A L, c \ni i}}\right)$ where $\overline{I_{H A L, c \ni l}}$ is the average carbon intensity of plants (in tons of $\mathrm{CO}_{2}$ per ton of clinker) in the country where the plant $i$ is located.

${ }^{39}$ This is defined as the natural $\log$ of the historical activity level of the plant divided by the average historical activity level in the country it is located (lnRelativePlantsize $i=\ln \left(H A L_{i} / \overline{H A L_{c \ni i}}\right.$ ) where $\overline{H A L_{c \ni l}}$ is the average historical activity level (in Mt of clinker) in the country where the plant $i$ is located.

${ }^{40}$ The dummy Coast is equal to one if the plant is located near the coast (less than $50 \mathrm{~km}$, this was done thanks to the geolocalization of the plants in the EUTL data). It concerns 61 plants out of 246.
} 
Constant -0.003

$(0.34)$

\begin{tabular}{lc}
\hline Observations & 737 \\
$\begin{array}{l}\text { Plant level fixed } \\
\text { effects }\end{array}$ & No \\
R2 & 0.21
\end{tabular}

Notes: * $p<0.1 ; * * p<0.0 \frac{\mathrm{R} 2}{* * * *} p<0.01$. Robust standard errors in parenthesis clustered at the country level. The dependent variable is the first differenced natural log of plant activity level. The sample includes 246 clinker producing plants identified as operating between 2010 and 2012, across 26 EU Member States, for the years 20082011.

Table 12 column (1) shows the results for the period 2008-2011 (post-crisis). Cement consumption has a statistically significantly effect on clinker production, with an estimated elasticity of 0.819 (hence if the demand at the country level decreases by $10 \%$, the production at the plant level decreases by $8.19 \%$ ). GDP is not statistically significant with an estimated elasticity of 0.235 . The relative plant size is not significant. Conversely, the carbon intensity of the plant has a negative effect, suggesting that production is lower in the most carbon intensive plants. Finally, the parameter Coastal is statistically significant and also negative. Production in coastal plants is lower by $4 \%$ in average than in inland plants. We could also have expected the opposite (coastal plants producing more, e.g. their production declining less, in order to export). This could reflect a strategy of cement companies to diminish production in coastal plants in the long run.

As a robustness check, we also estimate a fixed effects model which include plant level fixed effects to control for time invariant unobserved heterogeneity of clinker production behavior. Parameter estimates from the fixed effects regressions are similar suggesting that the combination of country-level fixed effects (implemented by first differencing) and time invariant plant level variables do a good job at controlling for heterogeneity in our random effects estimation. A number of further robustness tests were conducted. For example, we additionally ran the same specification using the correlated random effects model (Wooldridge 2010) and also tested the influence of other obtainable variables to predict clinker output including year dummies, lagged values, square terms. We found that the results were stable across the various estimators and specifications.

These parameters from column (1) are thus used to estimate counterfactual activity level. In order to give results robust to uncertainty, we use a semiparametric approach (Powell 1994) by specifically modelling the multiplicative error. The counterfactual plant activity level is then not fixed but is a random variable:

$$
\begin{aligned}
\text { Plantactlvity }_{l}^{C F-2012}= & \text { Plantactivity }_{i}^{2011} \times \exp \left(\widehat{\alpha_{0}}\right) \times\left(\frac{\text { CementConsum }_{c \ni i, 2012}}{\text { CementConsum }_{c \ni i, 2011}}\right)^{\widehat{\beta_{1}}} \times\left(\frac{G D P_{c \ni i, 2012}}{G D P_{c \ni i, 2011}}\right)^{\widehat{\beta_{2}}} \times \\
& \text { RelativeCo2intensity }_{i}^{\widehat{\gamma_{1}}} \times \text { RelativePantsize }_{i}^{\widehat{\gamma_{2}}} \times \exp \left(\widehat{\gamma_{3}} \text { Coast }_{i}\right) \times \exp (\tilde{\varepsilon})
\end{aligned}
$$

Extending the smearing estimate of Duan (1983), we first fit the distribution of $\tilde{\varepsilon}$ with a kernel density estimation like in Horowitz and Markatou (1996) which gives us its piecewise linear cumulative distribution function. The latter allows us simulating $\tilde{\varepsilon}$ (which has a standard deviation of 14\%) via inverse transform sampling. We perform a Monte Carlo simulation with 10,000 samples and report the average and the 95\% confidence interval in Table 5 and 6. 


\section{2 Country level net exports of clinker and cement estimation}

Counterfactual net exports of clinker and cement for each country are necessary to assess the channels of clinker disposal. A comprehensive analysis was not possible given the available data, and instead we use a simple first differenced estimation to control for country-level fixed effects and include cement consumption as the main explanatory variable. $^{41}$ This enables us to essentially extrapolate historic next export trends, whilst accounting for the influence of annual variation in cement consumption. The parameters are obtained from the following regression using data for the years 2008-2011 and 20 countries:

$$
\begin{aligned}
& \Delta N E_{K c, t}=\lambda_{0}+\lambda_{1} \Delta \text { CementConsum }_{c, t}+\varepsilon_{c, t} \\
& \Delta N E_{C j, t}=\mu_{0}+\mu_{1} \Delta \text { CementConsum }_{c, t}+\varepsilon_{c, t}
\end{aligned}
$$

For clinker net exports, the coefficient on $\lambda_{1}$ is -0.162 and this is significant at the $5 \%$ level. Hence on average, if cement consumption decreases by $1 \mathrm{Mt}$, clinker net exports increase by $0.16 \mathrm{Mt}$. The negative sign on $\lambda_{1}$ is inline with expectations. The fit is good for the clinker net exports $\left(R^{2}=0.41\right)$. For net cement exports, the coefficient on the cement consumption term is 0.025 and is not statistically significant at conventional levels. Changes in cement consumption thus do not predict changes in cement net exports and in this case the counterfactual is an extension of historic trends only. For a region $c$, we then compute counterfactual net exports as follows:

$$
\Delta N E_{K, j}^{C F 2012}=N E_{K, j}^{2011}+\widehat{\lambda_{1}} \Delta \text { CementConsm }_{c, 2012}
$$

and counterfactual next exports of cement as:

$$
\Delta N E_{C, j}^{C F 2012}=N E_{C, j}^{2011}+\widehat{\mu_{1}} \Delta \text { CementConsm }_{j, 2012}
$$

It should be noted that the cement consumption was remarkably low in 2012. Because of the consumption/export relationship established by the econometric model, clinker net exports would have risen anyway in 2012 compared to 2011 had the threshold rule not be implemented.

\footnotetext{
${ }^{41}$ As suggested by the Hausman test (if p-value are low, fixed effects are preferred), we used a fixed effect model. As the modified Wald test reveals the presence of heteroskedasticity, we present robust standard errors.
} 